\title{
Numerical analysis of stiffener for hybrid drive unite
}

\author{
Lenka Jakubovičová ${ }^{1, *}$, Milan Sága ${ }^{1}$, Marián Handrik ${ }^{1}$ \\ ${ }^{1}$ University of Žilina, Univerzitná 1, 01026 Žilina, Slovakia
}

\begin{abstract}
The matter of this article is a stress-strain analysis of hybrid drive prototype unit connected directly to convention Concrete Transit Mixer Gearbox. The unite was developed with intention to do field test on existing convection machines with possibility to use existing interfaces. The hybrid drive unit consists from electric and hydrostatic motor connected through addition mechanical transmission gearbox. The question is if today standard interface is good enough or need additional support a "stiffener". Two engineering design were analysed. The first one includes using the stiffener to fixate the construction of hybrid drive unite connected to the planetary gear. The second one is without the stiffener. For strain-stress analysis, a finite element software ANSYS Workbench was used.
\end{abstract}

Keywords: finite element method/FEM, hybrid drive unite, ANSYS Workbench

\section{Introduction}

In order to test this new technology on existing machines was necessary solved several challenges $[1,2,3]$. One of that challenge was do the field test on existing convention solution with possibility to connect hybrid drive unit to the main gearbox where is the same interface as is today for one motor only, Fig. 1. Designers needed to be sure that the stiffness of the subassembly will be stiff enough and from this reason was proposed to use additional support part „stiffener" see Figure 4. which was further analysed. The finite element method is especially used in the ground vehicle industry $[4,5,8,9,10]$.

The prototype hybrid drive unit for a mixing drum that is disposed on a motor vehicle which, as compared with the prior art, exhibits a further improvement to the efficiency of the drive system of the mixing drum and offering possibility eliminate unnecessary exhaust gas and noise emissions in a particular working arrears as underground and tunnels. The drive engine, in particular the internal combustion engine of the truck mixer, is capable of being shut down while the rotation of the mixing drum is maintained. The drive system will be capable of implementation inexpensively with little effort and robust and reliable in its realization.

\footnotetext{
* Corresponding author: lenka.jakubovicova@fstroj.uniza.sk

Reviewers: Robert Grega, Bohuš Leitner
} 


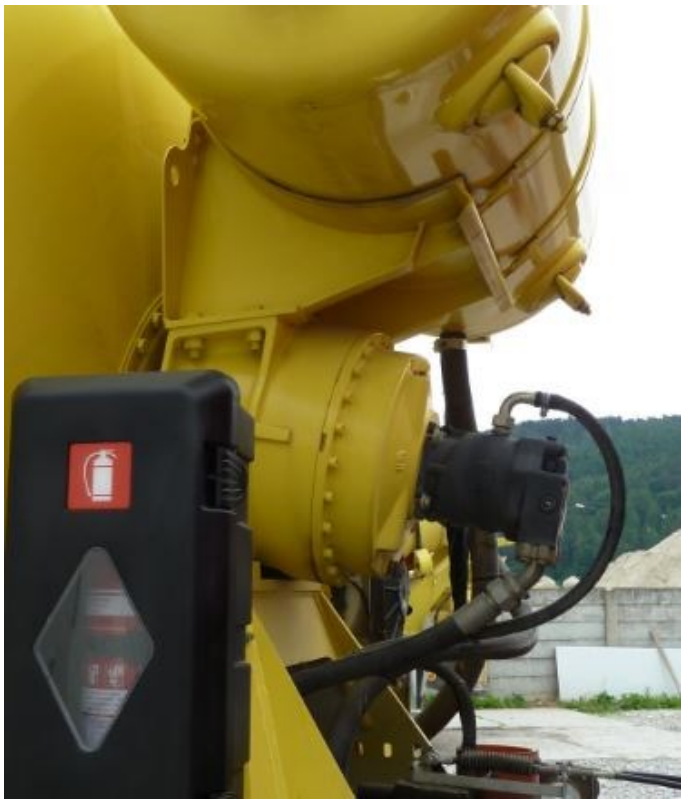

Fig. 1. Concrete Transit Mixer Application standard conventional solution

System was installing on the 4 years standard transit mixer with $9 \mathrm{~m}^{3}$ drum where the drum drive was updated from hydrostatic to hydroelectric, see Figs 2 and 3.

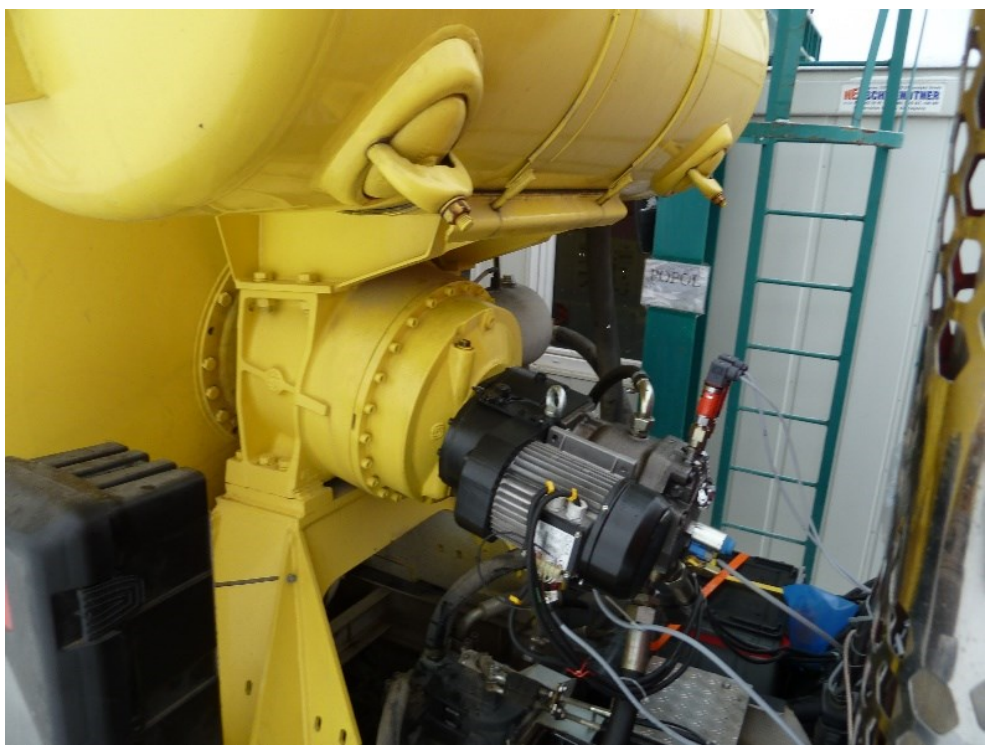

Fig. 2. Concrete Transit Mixer Application and prototype of hybrid drive unit

This object is achieved as a result of the fact that in addition to driving the mixing drum via a hydraulic drive train with displacement pump and hydraulic motor, the electric motor, with a relatively low output as compared with the hydraulic drive, is or can be permanently connected to the truck mixer gearbox in such a way that the mixing drum can be driven solely by the electric motor (Fig. 3). 


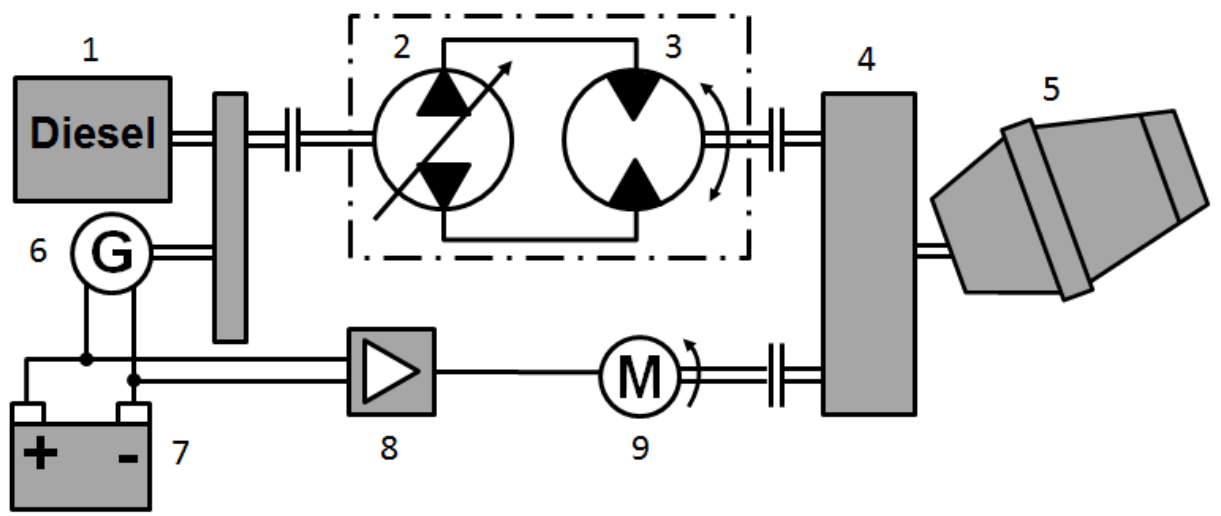

Fig. 3. The main components of a drive unit in a schematic illustration 1- Diesel engine, 2- Hydraulic pump, 3- Hydraulic motor, 4- Gearbox, 5- Drum, 6- Alternator, 7- Electric battery, 8- Inverter, 9- Electric motor

\section{Numerical analysis of stiffener for hybrid drive unite}

The main components of hybrid drive unite are on Figure 4.

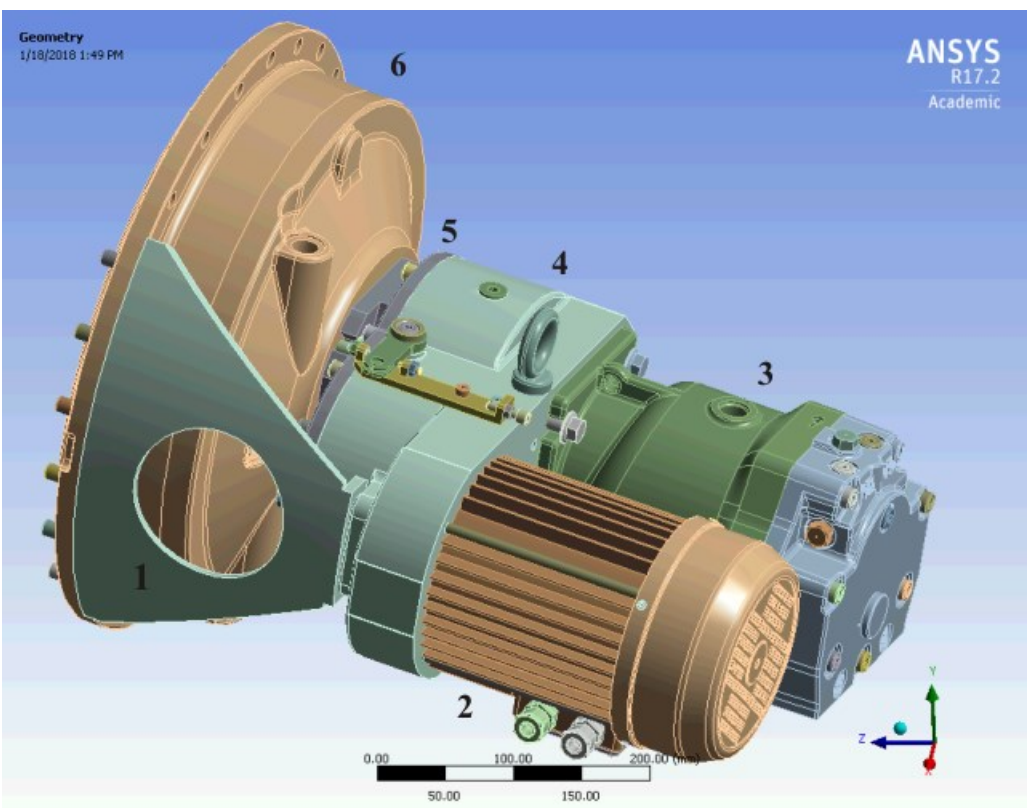

Fig. 4. The main components 1 - Stiffener, 2 - Electric motor, 3 - Hydrostatic motor, 4 - Sandwich Gearbox, 5 - Flange, 6 - Planetary gear cover

In the finite element analysis, only the main part consisted of stiffener, flange, planetary gear cover and sandwich gearbox was considered, Fig. 5. The mass of electric motor and hydrostatic motor was replaced with the resultant gravitational force acting in the centre of gravity, Fig. 5. 


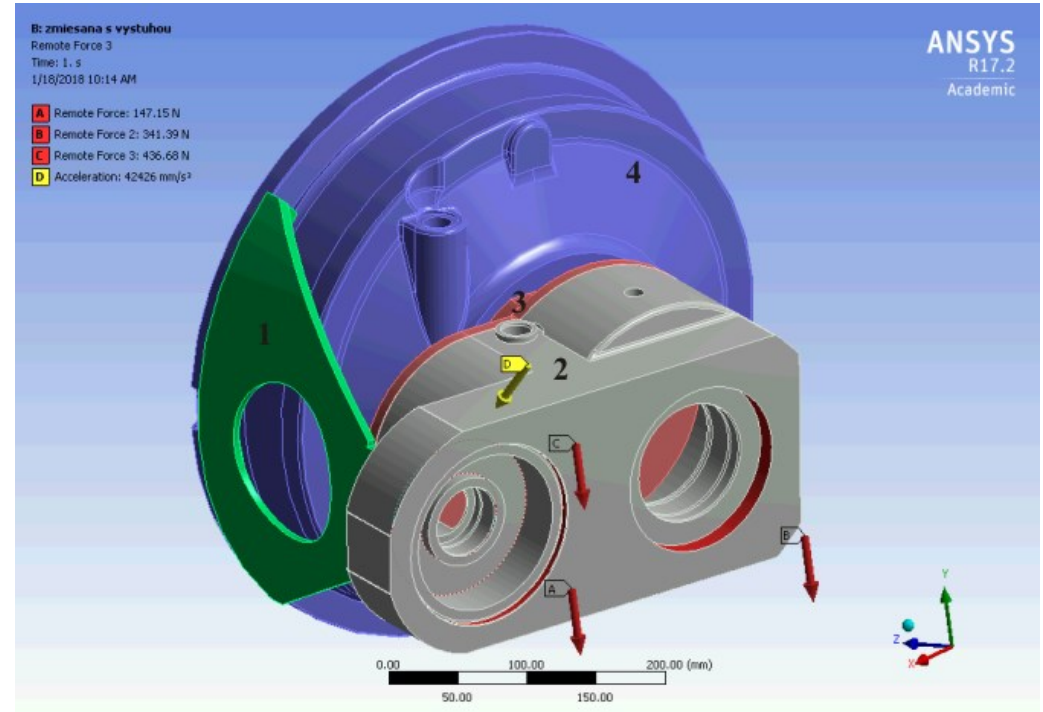

Fig. 5. The main components 1 - Stiffener, 2 - Gearbox, 3 - Flange, 4 - Planetary gear cover

At the planetary gear cover all degrees of freedom were defined - fixed support, the cover is firmly attached to the planetary gear box attached to the drum drive, Fig. 6 . Through the concrete transport was considered horizontal and vertical acceleration, Fig. 5.

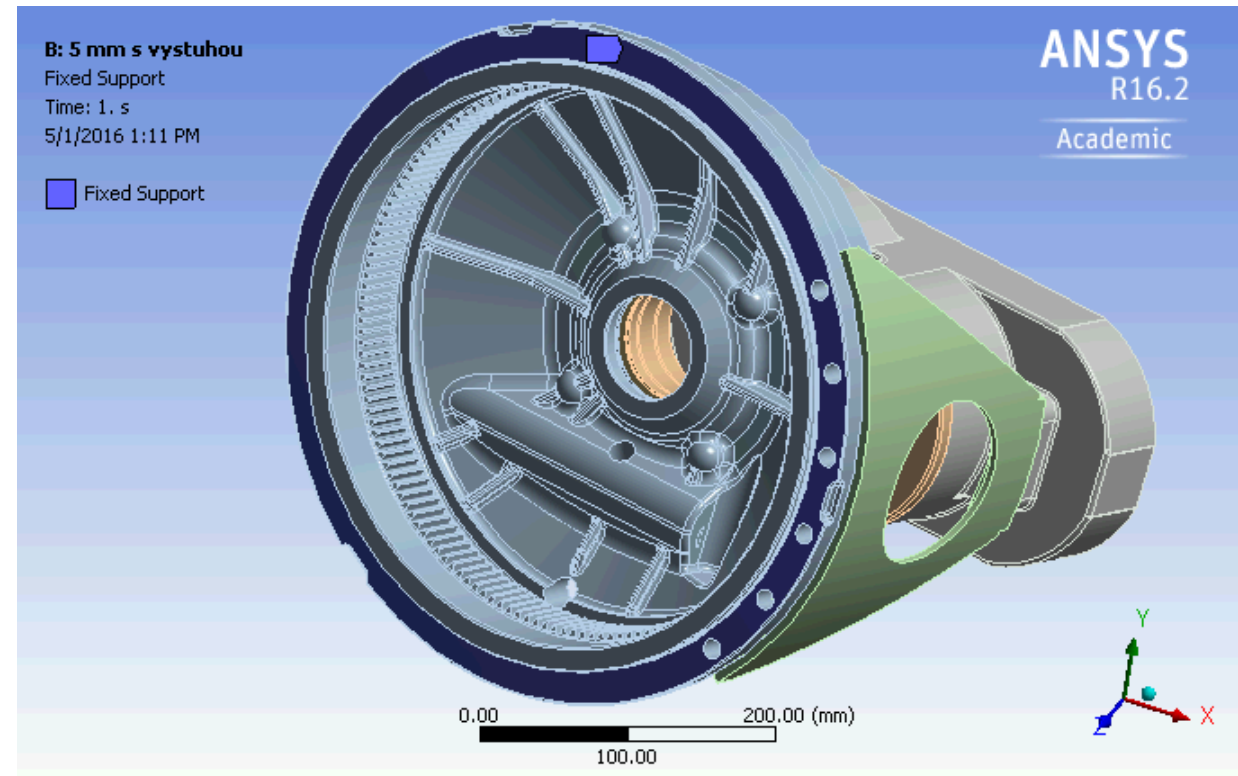

Fig. 6. Boundary condition - fixed support

Stress-strain analysis was carried out using the Ansys Workbench 16.2 software program, into which the model was imported and subsequently modified to a model suitable for finite-element analysis. The finite-element mesh was create by quadratic tetrahedron elements. Figure 7 shows flange and stiffener finite-element mesh and figure 8 shows planetary gear cover and gearbox finite-element mesh. 

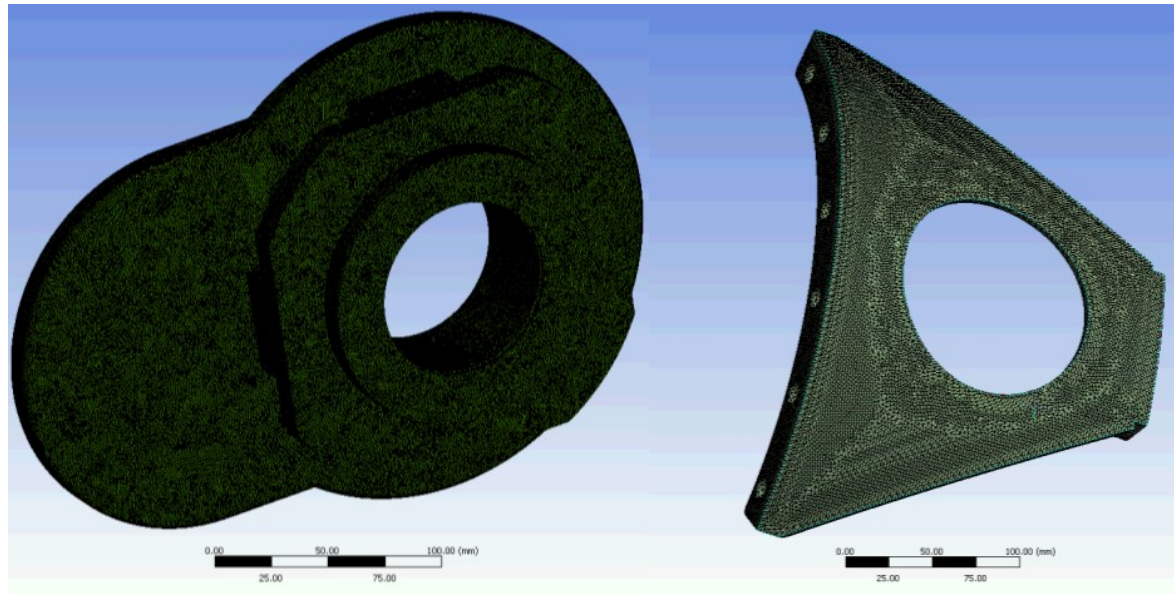

Fig. 7. Flange and stiffener finite-element mesh

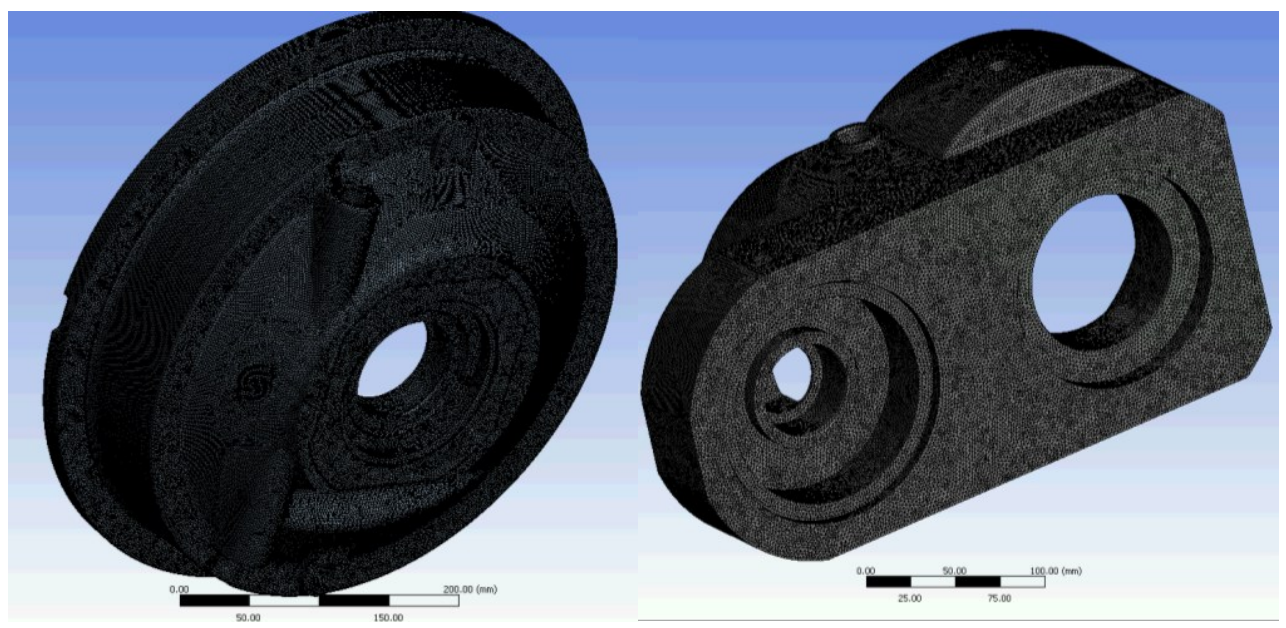

Fig. 8. Planetary gear cover and gearbox finite-element mesh

\section{Results}

The finite element analysis generated the maximum von Misses stress at the flange, see Figures $9-12$. For first design with stiffener von Misses stress reached $8.3599 \mathrm{MPa}$ and for second one von Misses stress reached 14.018 MPa, Table 1. Use the stiffener can increase stiffness of the subassembly by 40 percent. The maximum stress without the stiffener is enough below the permissible maximum value, and then the stiffener is no necessary to use and the prototype hybrid drive unit without the stiffener can withstand the load with the required safety level $[6,7]$. 


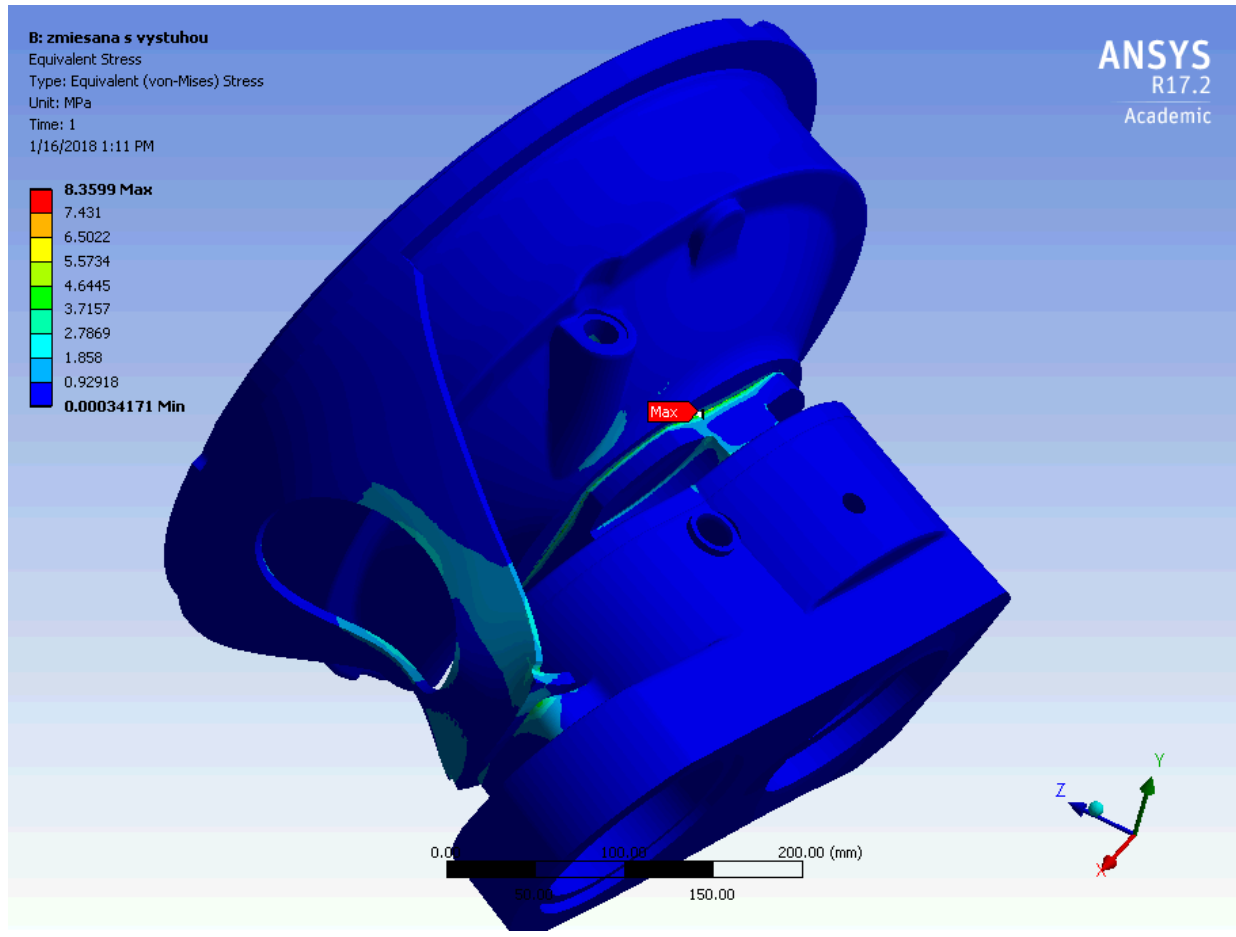

Fig. 9. Von Misses stress - block (with stiffener)

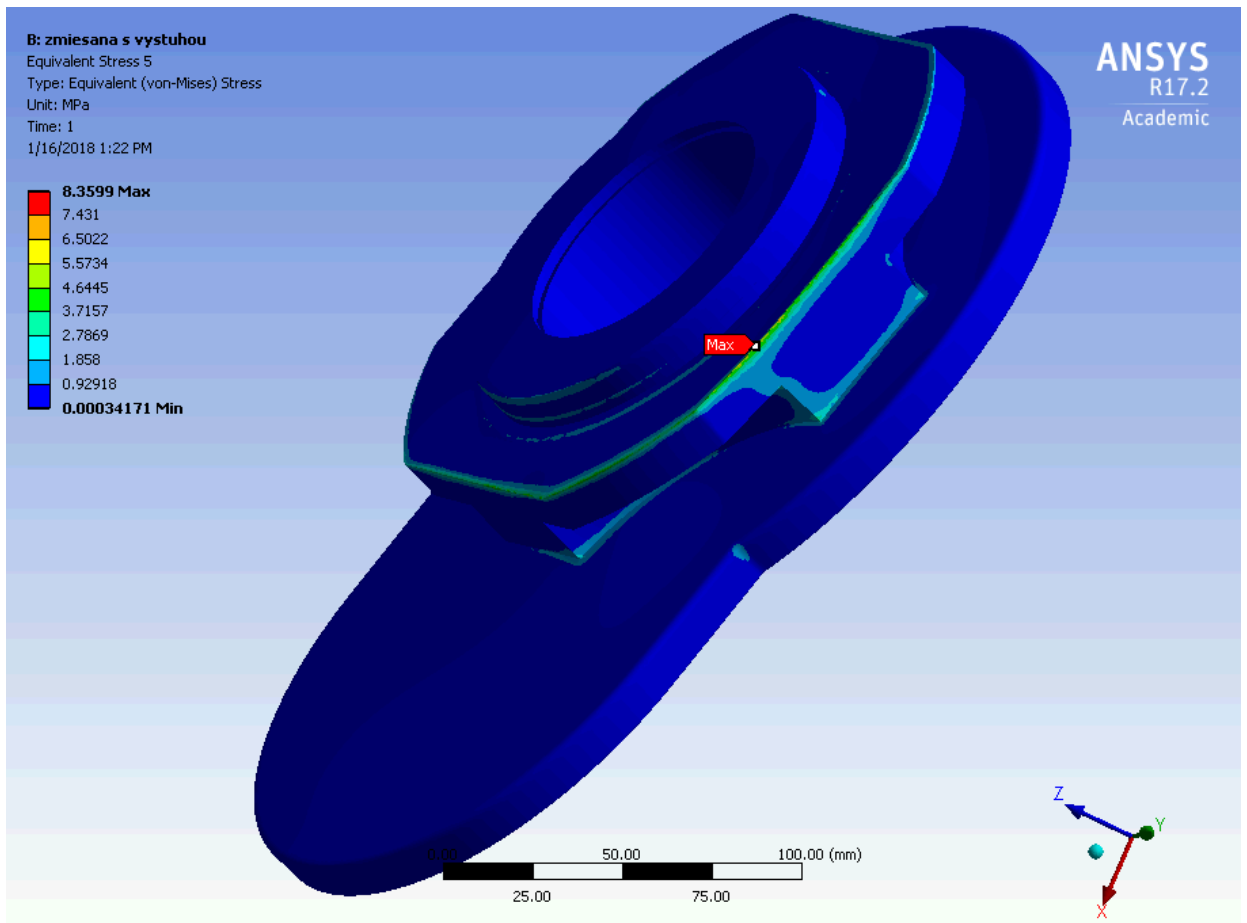

Fig. 10. Von Misses stress - flange (with stiffener) 


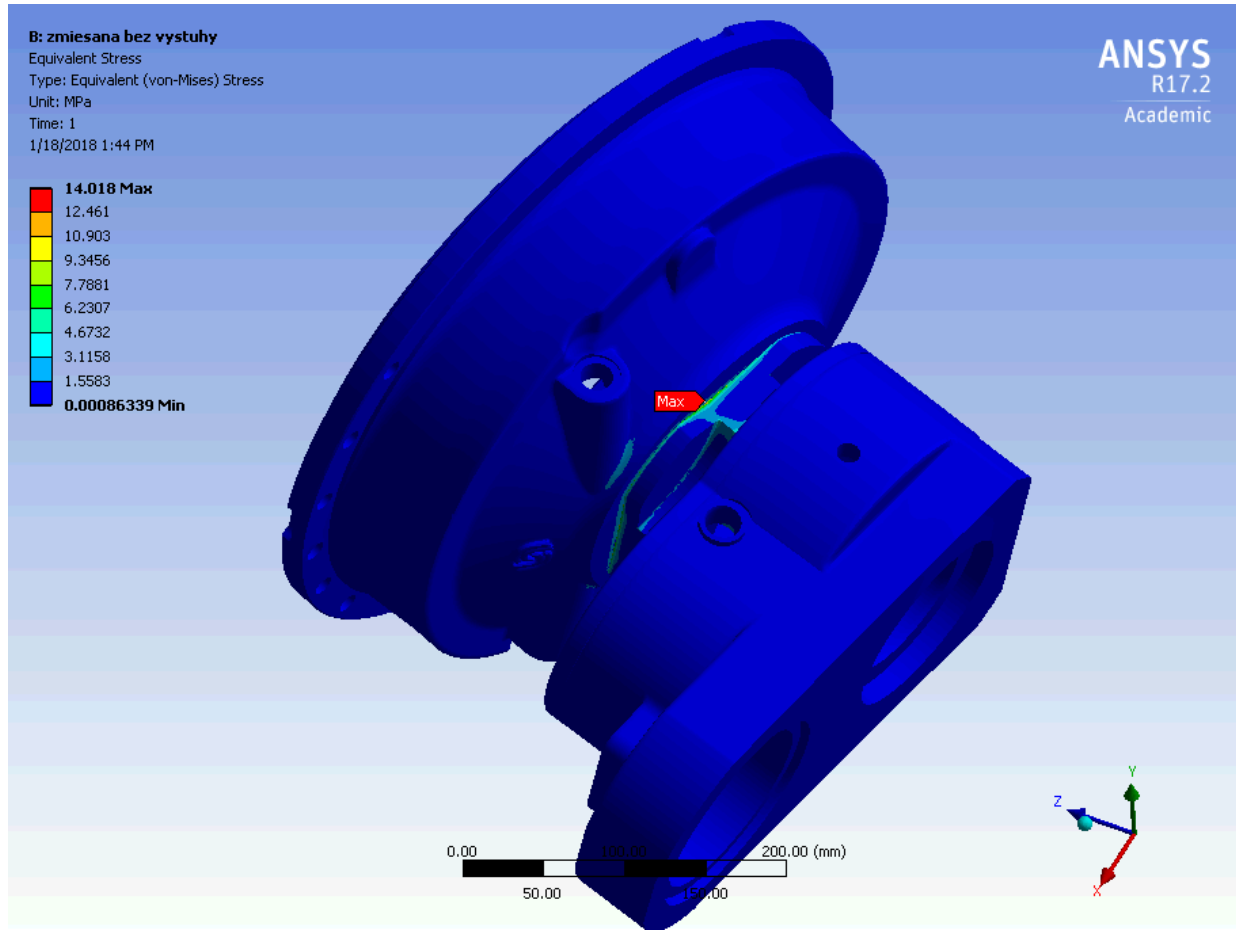

Fig. 11. Von Misses stress - block (without stiffener)

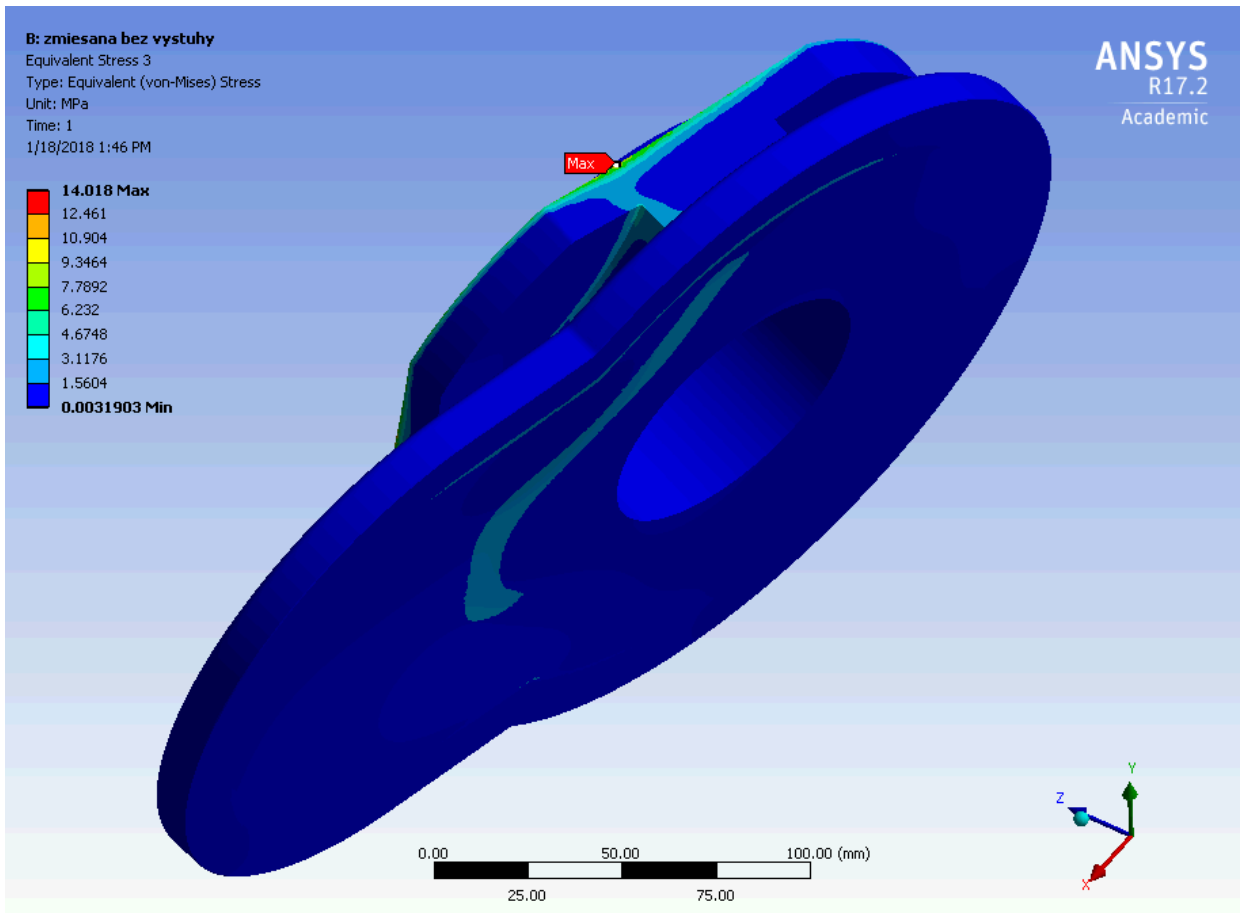

Fig. 12. Von Misses stress - flange (without stiffener) 
Table 1. Equivalent (von-Misses) stress

\begin{tabular}{|c|c|}
\hline & Equivalent Stress \\
\hline With stiffener & $8.3599[\mathrm{MPa}]$ \\
\hline Without stiffener & $14.018[\mathrm{MPa}]$ \\
\hline
\end{tabular}

\section{Conclusion}

The request was find out if the design proposal of the first prototype developed for field tests on existing machines is stiff enough or will be needed update stiffness or use a support part. Based on this request was developed stiffener, Fig. 5.

However at the end we can see based on result in table 1 that the design of prototype is stiff enough and is not necessary to do additional update was confirmed as well that with simple design proposal of stiffener can increase stiffness of the subassembly by $40 \%$ percent. This discovery can to the developing engineers possibility for future optimization and weight reductions if will be needed.

This work was supported by grant KEGA 015ŽU-4/2017 - Digital technologies for machine building study programs as a part of strategy "Internet of Things".

\section{References}

1. P. Zavadinka, R. Grepl, Energy saving potential of a hydrostatic drivetrain with variable charge pump. Proceedings of the 8th FPNI PH.D symposium on fluid power, (2014) ISBN 978-0-7918-4582-0

2. P. Zavadinka, R. Grepl, Cam ring force simulation for variable roller pump. Mechatronics 2013: Recent technological and scientific advances, 199-206 (2014) ISBN 978-3-319-02294-9

3. P. Zavadinka, Simulation of vehicle transport duty cycle with using of hydrostatic units control algorithm. Mechatronics 2011: Recent technological and scientific advances, 395-402 (2011) ISBN 978-3-642-23243-5

4. R. Grega, J. Krajňák, L. Žul'ová, G. Fedorko, V. Molnár, Failure analysis of driveshaft of truck body caused by vibrations. Engineering Failure Analysis 79, 208-215 (2017) ISSN 1350-6307

5. W. Piekarska, M. Kubiak, M. Žmindák, Issues in numerical modeling of phase transformations in welded joint. XXI Polish-Slovak Scientific conference machine modeling and simulations MMS 2016, Procedia Engineering 177, 141-148 (2017)

6. P. Kovacikova, R. Bezdedova, J. Jr.Vavro, J. Vavro, Comparison of numerical analysis of stress-strain states of cast iron with vermicular graphite shape and globular graphite shape. $20^{\text {th }}$ International conference machine modeling and simulations MMS 2015, Procedia Engineering 136, 28-32 (2016)

7. W. Piekarska, M. Kubiak, M. Vaško, Numerical estimation of the shape of weld and heat affected zone in laser-arc hybrid welded joints. Procedia Engineering 177, 114-120 (2017)

8. A. Vaško, M. Vaško, J. Belan, E. Tillová, Comparison of fatigue properties of nodular cast iron at low and high frequency cyclic loading. Procedia Engineering 177, 576-581 (2017) 
9. L. Zul'ova, R. Grega, J. Krajňák, G. Fedorko, V. Molnár, Optimization of noisiness of mechanical system by using a pneumatic tuner during a failure of piston machine. Engineering Failure Analysis 79, 845-851 (2017) ISSN 1350-6307

10. P. Pastorek, P. Novák, P. Kopas, M. Močilan, Finite element analysis of bond behavior in a steel reinforced concrete structure strengthened carbon fibre reinforced polymer ( $c$ frp) strips. Metalurgija 56 (3-4), 405-408, ISSN 0543-5846 